
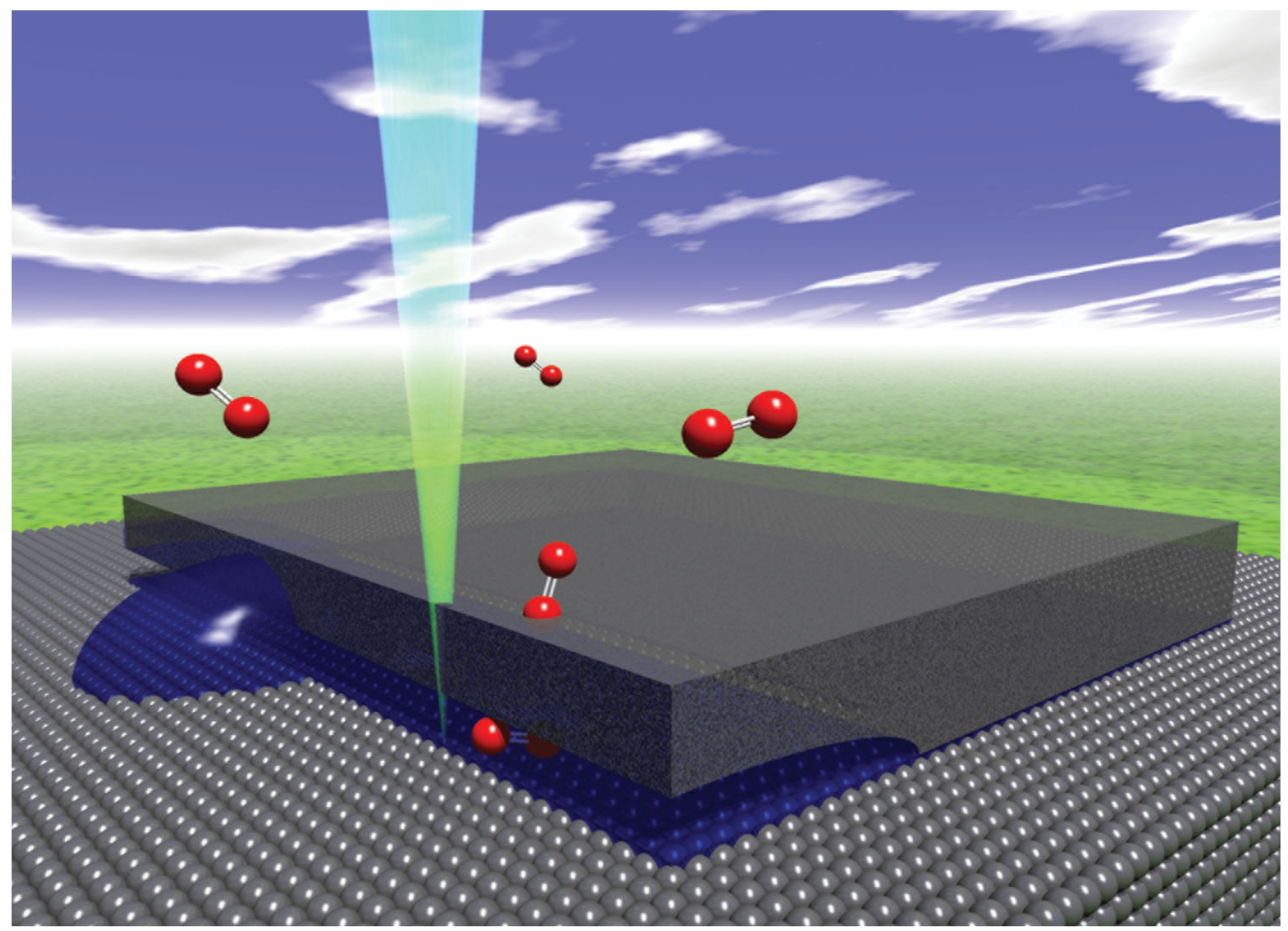

Showcasing research from Andreas Erbe's laboratory,

Max-Planck-Institut für Eisenforschung, Düsseldorf, Germany.

Solvent-starved conditions in confinement cause chemical oscillations excited by passage of a cathodic delamination front

The use of Raman spectroscopy to investigate the initial stages of a corrosion process at a polymer/metal interface reveals oscillations in $\mathrm{pH}$. These oscillations are caused by the limited supply of water as solvent and reagent.
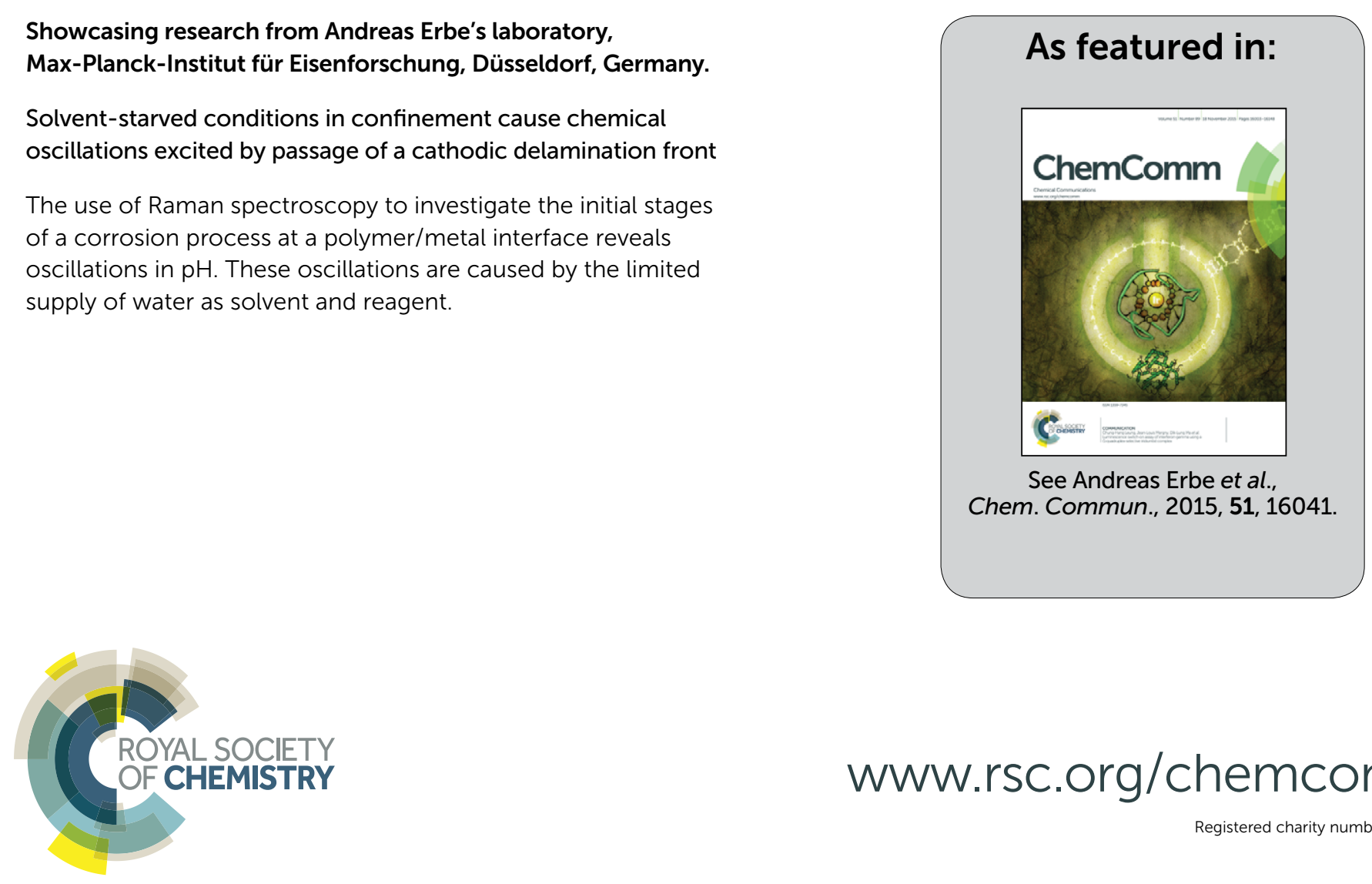


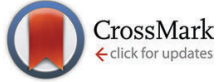

Cite this: Chem. Commun., 2015, 51,16041

Received 2nd August 2015, Accepted 26th August 2015

DOI: $10.1039 / \mathrm{c} 5 \mathrm{cc} 06468 f$

www.rsc.org/chemcomm

\section{Solvent-starved conditions in confinement cause chemical oscillations excited by passage of a cathodic delamination front}

\author{
Danish lqbal, Adnan Sarfraz, Martin Stratmann and Andreas Erbe*
}

\begin{abstract}
After passage of a delamination front at a polymer/zinc interface, $\mathrm{pH}$ oscillations and oscillations in the quantity of corrosion products are observed. The reason for these oscillations is the low quantity of water in the confined reaction volume, water consumption by oxygen reduction, and water regeneration after precipitation of $\mathrm{ZnO}$.
\end{abstract}

Confinement enables chemical processes which are not possible in bulk solution. Catalyst particles exhibit different catalytic activities inside carbon nanotubes compared to free particles. ${ }^{1,2}$ The inside of other carbon nanostructures, ${ }^{3-5}$ and silica networks can be used as "nanoreactors". 6,7 Spatial confinement was used to synthesize nanosheets. ${ }^{8,9}$ The ability to create confinement may have been crucial in the origin of life on the earth. ${ }^{10}$ Confinement enables the control of the characteristics of metal (electro)catalysts. ${ }^{11-13}$ In $\mathrm{O}_{2}$ electrochemistry, confinement affects reaction rates. ${ }^{14,15}$ Corrosion works differently in confinement, e.g. in "crevice corrosion", ${ }^{16}$ which has recently been monitored in real time. ${ }^{17}$ In corrosion protection, polymer coatings are frequently employed. During their deadhesion from the base metal substrate, a confined reaction volume is created, which shall be explored here. The most prominent mechanism of deadhesion of a polymer from steel and galvanised steel is the electrochemical process of cathodic delamination. ${ }^{18}$ Inspired from the wealth of precipitation patterns formed in chemical gardens, ${ }^{19}$ this work studies the corrosion of $\mathrm{Zn}$ in the confinement created after passage of a delamination front between $\mathrm{Zn}$ and delaminating poly(vinyl butyral) [PVB] as a model for a weakly protecting polymer coating.

The mechanism of cathodic delamination has been shown to start with the electrochemical $\mathrm{O}_{2}$ reduction (ORR) at a front, which propagates underneath the coating, with anodic metal dissolution and random formation of corrosion products following after the front. ${ }^{18,20-22}$ We will show that oscillations are observed in the quantity of corrosion products formed and

Max-Planck-Institut für Eisenforschung GmbH, Max-Planck-Str. 1, 40237 Düsseldorf, Germany. E-mail: a.erbe@mpie.de, aerbe@arcor.de; Fax: +492116792 218; Tel: +492116792890 in $\mathrm{pH}$ between a delaminating polymer and a $\mathrm{Zn}$ substrate after the passage of a cathodic delamination front.

For the experiments, zinc sheets $(1 \mathrm{~cm} \times 1 \mathrm{~cm} \times 1.5 \mathrm{~mm}$; purity 99.95\%; Goodfellow, Cambridge, UK) were initially mechanically polished using 4000 grit polishing paper and then cleaned ultrasonically in ethanol. The polished zinc sheets were spin coated with 10 weight $\%$ solution of PVB in ethanol (Sigma Aldrich) followed by drying in an oven at $70{ }^{\circ} \mathrm{C}$, to obtain $\sim 2-3 \mu \mathrm{m}$ thick polymer layers. Afterwards, a small defect in the polymer coating was created at the edge of the sample and the sample was placed on a zinc base plate. Then a small reservoir was built around the edge of the sample with the help of a fast drying two component adhesive to place an electrolyte.

To carry out in situ and operando Raman measurements, the assembly of the sample mounted on a zinc substrate was introduced into a custom made chamber with a glass window opening to allow spectral acquisition (Fig. 1). To minimize electrolyte evaporation, the humidity was controlled at $>90 \%$ by mixing humid and dry air with flow controllers. The in situ Raman spectra were recorded using a Horiba Jobin Yvon LabRAM confocal Raman microscope with an Argon ion laser source (emission at $514.342 \mathrm{~nm}$ ) and a power output of $12 \mathrm{~mW}$. The typical spectral acquisition time was in the range of 20 to $30 \mathrm{~s}$. The measurements were performed in backscattering geometry

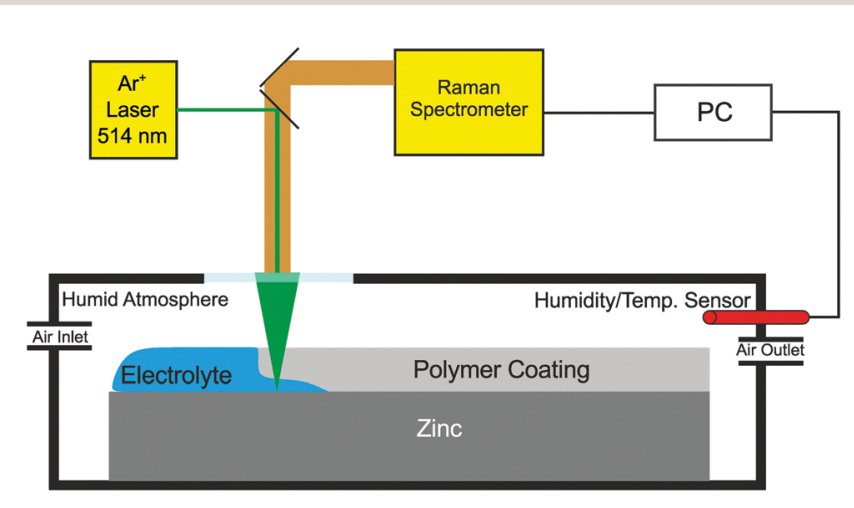

Fig. 1 Schematic view of the setup used for the experiments. 
with a long working distance $50 \times$-objective (numerical aperture 0.5 ) for sample illumination and scattered light collection. The laser spot size on the sample surface was approximately $10 \mu \mathrm{m}$ and it was focused roughly $2-3 \mathrm{~mm}$ away from the edge of the sample. To start the cathodic delamination process, the reservoir was filled with $1 \mathrm{M}$ aqueous $\mathrm{KCl}$ solution. During the in situ measurements, the laser was focused on the same spot throughout the experiment. (Mapping of the sample surface, though desirable, failed because (a) it is difficult to keep the focus at the polymer/metal interface inside the in situ cell during mapping and (b) because during mapping, information on the temporal and spatial dependence are interleaved.)

Raman spectra (examples in Fig. 2) show modes of the forming $\mathrm{ZnO}$ corrosion products, of $\mathrm{H}_{2} \mathrm{O}$, and of the PVB polymer layer. Raman spectra are analysed in the regions containing $\mathrm{ZnO}$ modes (wavenumber $\tilde{\nu} 360-660 \mathrm{~cm}^{-1}$ ) and water modes $\left(3050-3800 \mathrm{~cm}^{-1}\right.$ ). The $\mathrm{ZnO}$ region of the spectra is dominated by an $\mathrm{E}_{2}$ mode of wurzite $\mathrm{ZnO}$ at $\sim 440 \mathrm{~cm}^{-1}$, and its LO phonon at $570 \mathrm{~cm}^{-1}$. 23,24 The LO phonon of single crystalline Wurzite $\mathrm{ZnO}$ is inactive in the backscattering geometry used here; its observation in the spectra therefore shows the presence of defects, e.g. oxygen or zinc vacancies. ${ }^{25,26}$ The peak positions are stable throughout the experiments, except for a shift of the LO peak to higher wavenumbers in the first minutes of the experiment. Consequently, the average environment inside the $\mathrm{ZnO}$ lattice is not changing, except in the initial phase of the experiment. The changes affect the environment of defect sites.

Normalised Raman intensities $I_{\mathrm{N}}(\tilde{\nu})$ shown in Fig. 3a and $\mathrm{b}$ have been obtained for each individual spectrum by setting the spectrum's minimum intensity $I_{\min }$ to zero and the spectrum's maximum intensity $I_{\max }$ to 1 , i.e. as

$$
I_{\mathrm{N}}(\tilde{\nu})=\frac{I(\tilde{\nu})-I_{\min }}{I_{\max }-I_{\min }} .
$$

In the normalised intensities, oscillations are visible in the intensity of the ZnO modes (Fig. 3a and c). Intensity maxima

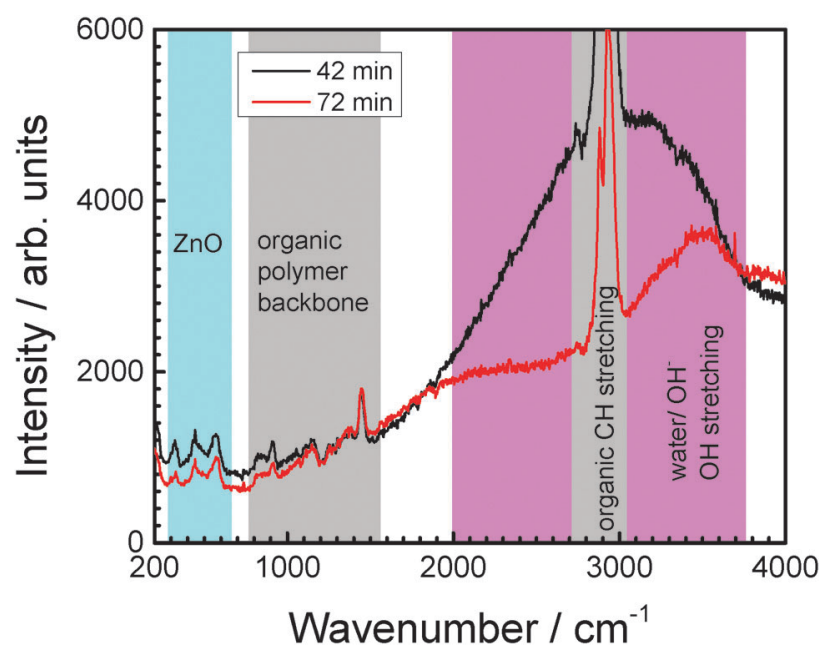

Fig. 2 Examples of in situ Raman spectra after two different delamination times as indicated on the graph. Regions with contributions from the different species in the system are labelled.
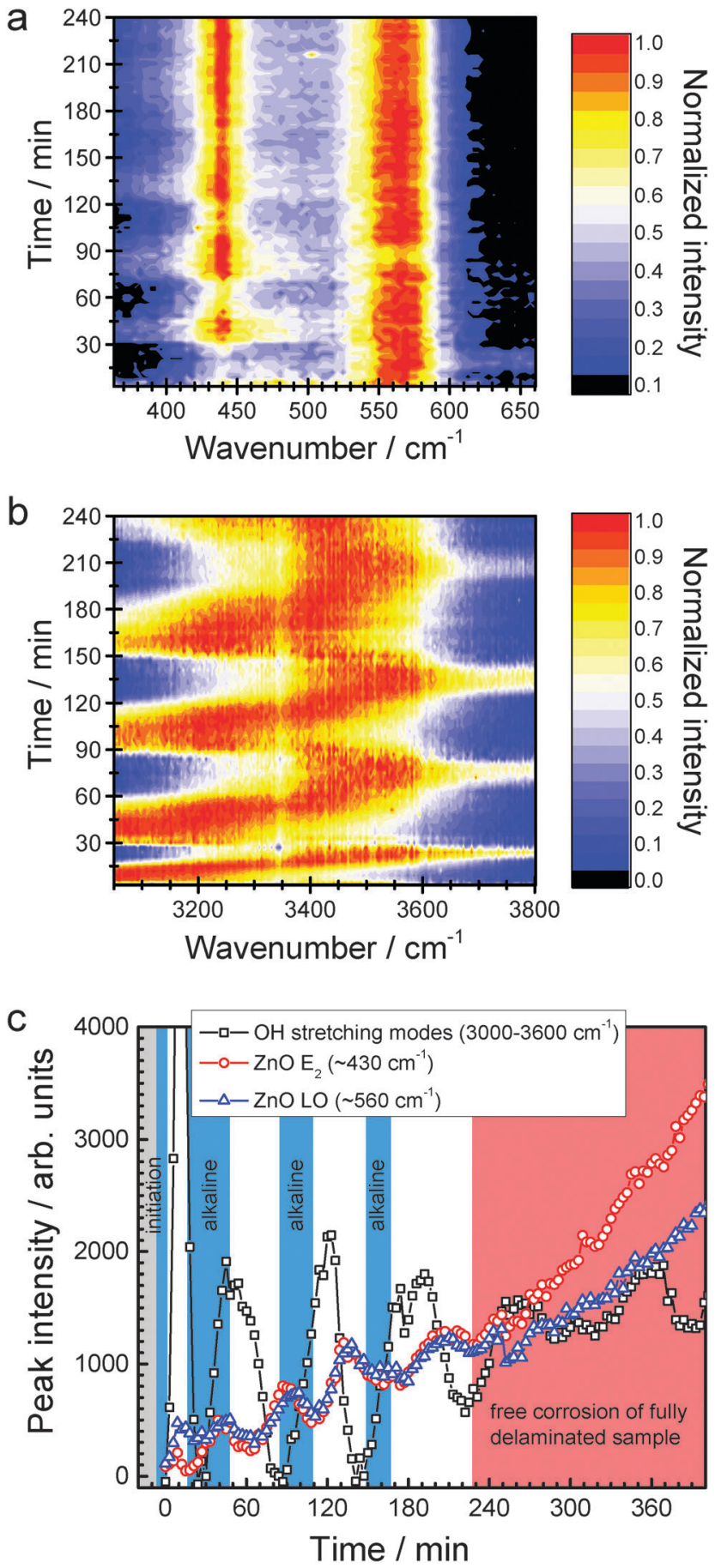

Fig. 3 Normalised Raman spectra in the regions dominated by (a) $\mathrm{ZnO}$ phonons and (b) OH stretching modes. Panel (c) shows the time dependence of the intensities at peak maxima. Times where the maximum of the $\mathrm{OH}$ stretching modes is below $3350 \mathrm{~cm}^{-1}$ are labelled "alkaline".

and minima are observed in both $\mathrm{ZnO}$ modes at the same times, i.e. there is no shift between the two curves. Because the observation of the LO phonon in backscattering geometry is closely related to defects, ${ }^{25,26}$ this observation excludes the possibility that oscillations between defect-rich and defect-poor $\mathrm{ZnO}$ occur. Rather, the amount of the $\mathrm{ZnO}$ corrosion product oscillates. On the other hand, the maximum intensity of the $\mathrm{OH}$ stretching 
modes is observed with a certain delay after the $\mathrm{ZnO}$ intensity maxima (Fig. 3c).

Maxima of the $\mathrm{OH}$ stretching modes of $\mathrm{H}_{2} \mathrm{O}$ clearly show oscillations (Fig. 3b), between $\approx 3170 \mathrm{~cm}^{-1}$ during intervals with increasing intensity of the $\mathrm{OH}$ stretching modes and $\approx 3500 \mathrm{~cm}^{-1}$ during decreasing $\mathrm{OH}$ intensities. A shift of the maximum to lower wavenumbers is indicative of higher $\mathrm{OH}^{-}$ concentration in water. ${ }^{27,28}$ Oscillations in intensity become obvious when plotting the Raman intensity at the maximum of the respective peak (Fig. 3c).

From scanning Kelvin probe investigations, a delamination rate of $\approx 3 \mathrm{~mm} \mathrm{~h}^{-1}$ has been determined. The oscillations terminate after $\approx 4 \mathrm{~h}$, which coincides with the time for delamination of the full, $1 \mathrm{~cm}$ long coated area.

Chemical oscillations are encountered in a number of chemical systems far from equilibrium. Mostly, an autocatalytic step is involved in the reaction, e.g. because one reaction product or intermediate blocks or catalyses a follow-up reaction in a multistep process. ${ }^{29}$ Chemical oscillations have especially been observed and exploited in heterogeneous multi-phase systems. ${ }^{30,31}$ When coupled to oscillating reaction, interesting dynamics can be observed in follow-up processes. ${ }^{32-36}$ Oscillations in $\mathrm{pH}$ can lead to propagating fronts, when coupling to dynamic aggregation of nanoparticles. ${ }^{37,38}$ Even phase formation and dissolution can oscillate. ${ }^{39}$

No oscillations have so far been reported in delamination processes. In electrochemical systems, however, oscillations and pattern formation have been observed, e.g. during dissolution of n-type $\mathrm{Si}^{40}$ On the example of $\mathrm{CO}$ electrooxidation, the mechanisms leading to oscillations involving several microelectrodes have been studied. With appropriate cooperativity, microscopic oscillations can be transformed into macroscopic patterns. ${ }^{41}$ In corrosion processes, local cathodes and local anodes are usually randomly distributed over the surface. ${ }^{21}$ Consequently, no oscillations are observed in a typical corrosion process. (Exceptions exist-oscillations in current and potential are observed e.g. in corrosion of stainless steels, ${ }^{42,43}$ of carbon steels or iron in acids, ${ }^{44-46}$ and copper, ${ }^{47}$ amongst others, mostly because of active-passive transitions.)

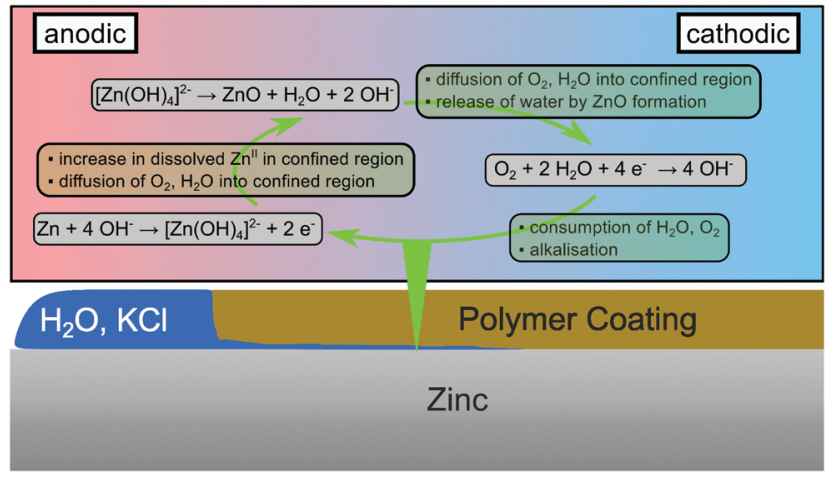

Fig. 4 Scheme of processes occurring consecutively after passage of a cathodic delamination front before complete delamination of the polymer coating.
The proposed mechanism which leads to the oscillations observed here is summarised in Fig. 4. At a cathodic delamination front, ORR proceeds under water consumption, ${ }^{48,49}$

$$
\mathrm{O}_{2}+2 \mathrm{H}_{2} \mathrm{O}+4 \mathrm{e}^{-} \rightarrow 4 \mathrm{OH}^{-} \text {. }
$$

The initial increase in the intensities of the $\mathrm{OH}$ stretching modes marks the approaching delamination front; the passage of the delamination front coincides with the initial maximum intensity of the $\mathrm{OH}$ modes. The quantity of water present between the metal surface and polymer film in the initial stages of delamination is small. Therefore, immediately after passage of the delamination front, the conditions are highly alkaline. ${ }^{48,49}$ According to classical kinetics, the rate of the ORR should hence decrease. In the illuminated region $(\sim 10 \mu \mathrm{m})$, the beginning of $\mathrm{ZnO}$ formation is closely associated with this passage of the delamination front. The ORR subsequently consumes water and produces $\mathrm{OH}^{-}$. The alkaline conditions thus created lead to dissolution of the initially formed $\mathrm{ZnO}$. After the delamination front has moved on, the surface becomes anodic, featuring metal dissolution. At $\mathrm{pH}>12$, set by the conditions created as a result of ORR, Zn dissolution occurs according to ref. 50:

$$
\mathrm{Zn}+4 \mathrm{OH}_{\mathrm{aq}}{ }^{-} \rightarrow\left[\mathrm{Zn}(\mathrm{OH})_{4}\right]_{\mathrm{aq}^{2-}}+2 \mathrm{e}^{-} .
$$

An increase in the concentration of soluble $\mathrm{Zn}$ species together with a decrease in $\mathrm{pH}$ due to the binding of $\mathrm{OH}^{-}$inevitably makes the formation of the solid corrosion product $\mathrm{ZnO}$ favourable, which forms as

$$
\left[\mathrm{Zn}(\mathrm{OH})_{4}\right]_{\mathrm{aq}}{ }^{2-} \rightarrow \mathrm{ZnO}+\mathrm{H}_{2} \mathrm{O}+2 \mathrm{OH}_{\mathrm{aq}}{ }^{-},
$$

under water release, possibly via $\mathrm{Zn}(\mathrm{OH})_{2}$ as an intermediate. ${ }^{50}$ The corresponding Raman spectra show increasing intensities of $\mathrm{ZnO}$ and $\mathrm{OH}$ modes. $\mathrm{ZnO}$ formation results in an increase in the number of available water molecules triggering a restart of the ORR, this time on a ZnO-coved surface, where $\mathrm{O}_{2}$ was accumulated again. The observed potentials are known from Kelvin probe measurements to permit the reduction of $\mathrm{O}_{2} \cdot{ }^{20}$ The consequence is alkalisation, dissolution of the formed $\mathrm{ZnO}$, hence a decrease of the intensities of the $\mathrm{ZnO}$ modes. Alkalisation and consumption of water will stop the ORR again at some point, making the region anodic, with the start of the next cycle. ZnO peak intensities oscillate with an increasing slope of the running average. This increase is consistent with the release of only one water molecule per unit of $\mathrm{ZnO}$ formed, while in the ORR, (at least) two water molecules are needed for one $\mathrm{O}_{2}$ molecule to be reduced, so that full regeneration of initial conditions is impossible. As water is also present in solvation shells of the dissolved species, the species mentioned in reactions 2-4 do not represent all water molecules participating in the process.

When the polymer coating is fully delaminated, the confined reaction volume disintegrates as no interaction prevents water from spreading on the metal. The consequence is an overall excess of water and the standard monotonous growth of corrosion products.

In conclusion, the ORR at a cathodic delamination front excites chemical oscillations, including an oscillating $\mathrm{pH}$, on corroding $\mathrm{Zn}$. The oscillations involve the formation of a solid 
$\mathrm{ZnO}$ phase. Because the solvent and reagent water is present in limited amounts (in analogy to the "crowded" situation in a cell), ${ }^{51}$ oscillations are sustained until the sample is fully delaminated. Consequently, after passage of the delamination front, not only the quantity of free water, but also the $\mathrm{pH}$ oscillates over a large range. It is unique in the investigated system that the solvent itself takes part in the feedback mechanism leading to oscillations. The observation of oscillations also shows that correlated and not random cathode-anode-structures are present in a delaminating system. ${ }^{18,21,22}$ In the field, full delamination is rarely observed, and confinement can be sustained for long times. Modern self-healing concepts are thus only viable if these oscillations are suppressed, or a redox-triggered self-healing mechanism is used. ${ }^{52}$

D.I. acknowledges a scholarship from the IMPRS SurMat. A.S. acknowledges support from the Max Planck Society through MaxNet Energy. This work is supported by the Cluster of Excellence RESOLV (EXC 1069) funded by the Deutsche Forschungsgemeinschaft.

\section{References}

1 F. Zhang, X. Pan, Y. Hu, L. Yu, X. Chen, P. Jiang, H. Zhang, S. Deng, J. Zhang, T. B. Bolin, S. Zhang, Y. Huang and X. Bao, Proc. Natl. Acad. Sci. U. S. A., 2013, 110, 14861-14866.

2 J. Xiao, X. Pan, S. Guo, P. Ren and X. Bao, J. Am. Chem. Soc., 2015, 137, $477-482$.

3 S. A. Miners, G. A. Rance and A. N. Khlobystov, Chem. Commun., 2013, 49, 5586-5588.

4 G. A. Rance, W. A. Solomonsz and A. N. Khlobystov, Chem. Commun., 2013, 49, 1067-1069.

5 C. Galeano, J. C. Meier, V. Peinecke, H. Bongard, I. Katsounaros, A. A. Topalov, A. Lu, K. J. J. Mayrhofer and F. Schüth, J. Am. Chem. Soc., 2012, 134, 20457-20465.

6 R. Gounder and E. Iglesia, Chem. Commun., 2013, 49, 3491-3509.

7 S. Alberti, G. J. A. A. Soler-Illia and O. Azzaroni, Chem. Commun., 2015, 51, 6050-6075.

8 S. C. Junggeburth, L. Diehl, S. Werner, V. Duppel, W. Sigle and B. V. Lotsch, J. Am. Chem. Soc., 2013, 135, 6157-6164.

9 H. Zhu, C. Xiao, H. Cheng, F. Grote, X. Zhang, T. Yao, Z. Li, C. Wang, S. Wei, Y. Lei and Y. Xie, Nat. Commun., 2014, 5, 3960.

10 P. L. Urban, New J. Chem., 2014, 38, 5135-5141.

11 L. Li, H. Zhao, J. Wang and R. Wang, ACS Nano, 2014, 8, 5352-5364.

12 C. Cui, L. Gan, M. Neumann, M. Heggen, B. Roldan Cuenya and P. Strasser, J. Am. Chem. Soc., 2014, 136, 4813-4816.

13 Y.-Z. Chen, Q. Xu, S.-H. Yu and H.-L. Jiang, Small, 2015, 11, 71-76.

14 J. Snyder, K. Livi and J. Erlebacher, Adv. Funct. Mater., 2013, 23, 5494-5501.

15 A. D. Doyle, J. H. Montoya and A. Vojvodic, ChemCatChem, 2015, 7, 738-742.

16 H. Kaesche, Corrosion of Metals: Physicochemical Principles and Current Problems, Springer, Berlin, Germany, 2003.

17 B. R. Shrestha, Q. Hu, T. Baimpos, K. Kristiansen, J. N. Israelachvili and M. Valtiner, J. Electrochem. Soc., 2015, 162, C327-C332.
18 G. Grundmeier and S. Alda, in Encyclopedia of Electrochemistry, ed. A. Bard, M. Stratmann and G. Frankel, Wiley-VCH, Weinheim, Germany, 2007, vol. 4, ch. Corrosion Protection by Organic Coatings, pp. 500-566.

19 F. Haudin, J. H. E. Cartwright, F. Brau and A. De Wit, Proc. Natl. Acad. Sci. U. S. A., 2014, 111, 17363-17367.

20 W. Fürbeth and M. Stratmann, Corros. Sci., 2001, 43, 207-227.

21 H. Leidheiser Jr., W. Wang and L. Igetoft, Prog. Org. Coat., 1983, 11, 19-40.

22 J. H. W. de Wit, D. H. van der Weijde and G. Ferrari, in Corrosion Mechanisms in Theory and Practice, ed. P. Marcus, CRC Press, Boca Raton, USA, 3rd edn, 2012, ch. Organic Coatings, pp. 863-906.

23 T. C. Damen, S. P. S. Porto and B. Tell, Phys. Rev., 1966, 142, 570-574.

24 Ü. Özgür, Y. I. Alivov, C. Liu, A. Teke, M. A. Reshchikov, S. Doğan, V. Avrutin, S.-J. Cho and H. Morkoç, J. Appl. Phys., 2005, 98, 041301.

25 Y. Y. Tay, T. T. Tan, M. H. Liang, F. Boey and S. Li, Appl. Phys. Lett., 2008, 93, 111903.

26 Y. Chen, P. Schneider, B.-J. Liu, S. Borodin, B. Ren and A. Erbe, Phys. Chem. Chem. Phys., 2013, 15, 9812-9822.

27 W. R. Busing and D. F. Hornig, J. Phys. Chem., 1961, 65, 284-292.

28 G. E. Walrafen and R. T. W. Douglas, J. Chem. Phys., 2006, 124, 114504.

29 D. Kondepudi and I. Prigogine, Modern Thermodynamics, Wiley, Chichester, 1998.

30 G. Ertl, Angew. Chem., Int. Ed., 2008, 47, 3524-3535.

31 S. Mann, Nat. Mater., 2009, 8, 781-792.

32 J. R. Howse, P. Topham, C. J. Crook, A. J. Gleeson, W. Bras, R. A. L. Jones and A. J. Ryan, Nano Lett., 2006, 6, 73-77.

33 L. Donlon and K. Novakovic, Chem. Commun., 2014, 50, 15506-15508. 34 Y. Chen and C. Mao, Small, 2008, 4, 2191-2194.

35 T. Liedl and F. C. Simmel, Nano Lett., 2005, 5, 1894-1898.

36 I. Molnar, K. Kurin-Csorgei, M. Orban and I. Szalai, Chem. Commun., 2014, 50, 4158-4160.

37 I. Lagzi, B. Kowalczyk, D. Wang and B. A. Grzybowski, Angew. Chem., Int. Ed., 2010, 49, 8616-8619.

38 H. Nabika, T. Inumata, H. Kitahata and K. Unoura, Colloids Surf., A, 2014, 460, 236-239.

39 K. Kurin-Csörgei, I. R. Epstein and M. Orbán, Nature, 2005, 433, 139-142.

40 K. Schönleber, C. Zensen, A. Heinrich and K. Krischer, New J. Phys., 2014, 16, 063024.

41 D. A. Crespo-Yapur, A. Bonnefont, R. Schuster, K. Krischer and E. R. Savinova, ChemPhysChem, 2013, 14, 1117-1121.

42 S. Jones, K. Coley and J. Kish, Corrosion, 2013, 69, 543-550.

43 S. R. Street, W. Xu, M. Amri, L. Guo, S. J. M. Glanvill, P. D. Quinn, J. F. W. Mosselmans, J. Vila-Comamala, C. Rau, T. Rayment and A. J. Davenport, J. Electrochem. Soc., 2015, 162, C457-C464.

44 Y. Zhu, L. Li and C. Wang, Corros. Sci., 2015, 94, 445-451.

45 D. Sazou, A. Kominia and M. Pagitsas, J. Solid State Electrochem., 2014, 18, 347-360.

46 T. Kado and N. Kunitomi, J. Electrochem. Soc., 1991, 138, 3312-3321.

47 N. I. Potkonjak, Z. Nikolić, S. R. Anić and D. M. Minić, Corros. Sci., $2014,83,355-358$.

48 A. Leng, H. Streckel and M. Stratmann, Corros. Sci., 1998, 41, 547-578.

49 A. Leng, H. Streckel and M. Stratmann, Corros. Sci., 1998, 41, 579-597.

50 X. G. Zhang, Corrosion and Electrochemistry of Zinc, Plenum Press, New York, USA, 1996.

51 D. Gnutt, M. Gao, O. Brylski, M. Heyden and S. Ebbinghaus, Angew. Chem., Int. Ed., 2015, 54, 2548-2551.

52 A. Vimalanandan, L.-P. Lv, T. H. Tran, K. Landfester, D. Crespy and M. Rohwerder, Adv. Mater., 2013, 25, 6980-6984. 